\title{
E-Reserve Redefined: One Canadian Library Experience
}

\section{Ophelia Cheung}

Ryerson University

\section{digital.library.ryerson.ca/object/336}

\section{Please Cite:}

Cheung, O. (2012). E-reserve redefined: One Canadian library experience. Proceedings of the Peking University Library $110^{\text {th }}$ Anniversary International Conference on Change and Challenge: Redefining the Future of Academic Libraries \& the Pacific Rim Digital Library Alliance (PRDLA) 2012 Annual Meeting.

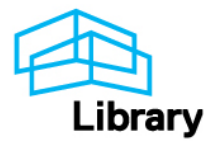




\section{E-Reserve Redefined: One Canadian library experience}

\section{Introduction}

\section{Definition of e-reserve and how it stacks up with other library services}

Among the public services offered by academic libraries, e-reserve is probably the least welldefined in scope and delivery. "Circulation" refers clearly to borrowing of materials, through the library staff or more recently, the self-check machines. "Reference" staff assist users in their research, utilizing the library collection, physical or online, and resources outside the library. Other services are shown to be responding quickly to societal and technological changes. The "library space" has gained a new dimension. The "Learning Commons" accommodates computing facilities and "centres" in the library space, such as the "Writing Centre", the "Math Centre" and the "Student Learning Support Centre", catering to different stages of the research process. The "library space" incorporates coffee shops, mobile furniture and wireless access everywhere, and becomes the stage for cultural events, art exhibits and other outreach functions. Librarians are no longer confined to the library's physical space. They conduct virtual reference - email or chat, sometimes on a shared initiative, serving users from multiple institutions. They integrate subject research guides into the course management systems, or serve as collaborators with faculty in designing course content. Indeed, libraries and librarians' roles are changing to keep up with changes that support mobility, versatility, diversity, interactivity and collaboration.

Most people perceive e-reserves as providing 24/7 access to electronic materials - book chapters, journal articles and streamed videos that are assigned readings for students. This is the narrowest definition, equating e-reserves to the electronic counterpart of the traditional "print" reserves, facilitating access to physical materials by making the loan periods shorter (e.g. 2 hours, one day). E-reserves are not seen to be as responsive to the societal and technological changes as prominently as reference, instruction, and the new definition of library as space. Because many institutions regard e-reserves as separate entities and use stand-alone systems, it leads to the impression that "E-reserves, as a service offered by the library, may have had a short lifespan...These viable alternatives may mean that a function that was once core to access services, demanding a lot of staff time, will fade into the background in the near future." (Carver, 2010)

Compared with other library services, e-reserves are varied in scope and delivery. In my coauthored book (Cheung, 2010) on "New Approaches to E-Reserve: linking, sharing and streaming", multiple access points to e-reserves are identified. There are the ILS or Integrated Library Systems approach (i.e. through the library catalogue) and the dedicated e-reserve system approach, which includes proprietary systems such as Docutek ERes and Atlas' Ares or open source systems (ReservesDirect developed by Emory University Libraries in the U.S. ). Ereserve can be delivered through a CMS (course management system) such as Blackboard, 
Moodle and Desire2Learn or a hybrid, integrating a reserves system with a CMS. The content can be migrated to an institution-wide repository of teaching and learning materials, as in the case of the University of Western Australia (Poleykett, 2003). Some institutions adapt RefWorks, a citation management software, to combine research, e-reserves and instructorstudent interaction into one platform. The content of e-reserves also differs. To avoid the copyright permissions process, some institutions limit to only library subscribed materials or instructors' creations e.g. lectures, exams. The e-reserve process can be "full service", with library staff handling it from start to finish, checking availability in the library collection, posting stable links or scanning to pdfs before uploading for faculty, liaising with publishers for transactional permissions and paying the cost from library funds. At the other end of the scale is "self-service", with minimal library input besides offering tips to faculty on creating links and copyright analysis. There could also be a hybrid approach, with partial library involvement. Ereserves, being a service most impacted by copyright, often take on the leadership role in promoting copyright literacy on campus and enforcing compliance. E-reserves have evolved to such an extent that Hersey (2005) remarked that they should become part of a new "course support" unit, scanning and linking documents for electronic access, disseminating copyright information, supporting instructional technology and informing faculty of instructional opportunities on campus.

\section{E-Reserve reflects general library trends}

E-Reserve development at Ryerson University Library in Canada provides exemplary evidence of the societal and technological changes - the shift in user culture, and increased collaboration with other stakeholders on campus. Ryerson University is Canada's leader in career-focused education, offering more than 100 undergraduate, Master's and PhD programs and with 26,000 undergraduate and 2,300 graduate students. The School of Continuing Education, the country's largest, offers 1,400 courses and 80 certificate programs. Since its inception in 2004, Ryerson's E-Reserve has moved from delivering course readings in the library catalogue to Blackboard in 2005. It experimented with RefWorks in 2007 and integrated Ares, a commercial system, with Blackboard in 2011. It collaborated in 2012 with the Campus Bookstore to provide a "One-Stop Course Readings" service, making the library the main conduit for checking copyright for all three services - print reserves, e-reserves and course packs, and the central copyright repository for all formats, including audiovisuals. The E-Reserve unit is the driving force behind crosstraining of staff within the Borrowing \& Lending Services, of which E-Reserve is a part. Every library technician in the Services was trained to process e-reserve, and every Circulation assistant trained to scan documents. Ryerson Library's e-reserve experiences are a microcosm of recent developments in the library landscape: a new user culture that values mobility, portability, online access, engagement, social interaction and personal expression, an integration with the campuswide teaching/learning portal that includes all formats of materials, and a new way of defining library presence in the convergence of services, on and off campus. An analysis of its 
development reveals the underlying concepts that help to shape the future of academic libraries and the issues and challenged encountered.

\section{Concept One: Instant access}

\section{Video streaming}

The concept of Users Behavior and Expectations was listed among the 2012 Top Ten Trends in Academic Libraries (ACRL, 2012). "The new library should be based on the just-in-time model, where access is more important than vast quantities of nearby inventory". In addition to textual materials such as journal articles and ebooks, students these days want just-in-time access to multimedia, same as they freely enjoy YouTube videos as entertainment, news capturing or social interaction. As early as in 2005 , Ryerson Library began to add video streaming links to ereserves. Technically, it is possible but there are copyright concerns in both the digitization of videos and streaming of YouTube videos. The licences of digitizing educational videos, and feature films in particular, are often prohibitive in cost. For decades, the Canadian Copyright Act did not have an "education" exception to copying, other than for the purpose of private study, research, news reporting and criticism. The recent changes in the copyright legislation will liberalize the display of digital content. However, the application of "fair dealing", a principle of users' rights, is complicated, and often requires the assistance of a copyright specialist. For example, YouTube usage may involve tracing the rights ownership and checking terms of use, a process which students or faculty are not prepared to undertake.

\section{Direct linking vs. OpenURL}

When Ryerson launched its e-reserve service, links to articles were attached to the Library catalogue. After migrating to Blackboard, staff utilized the SFX OpenURL form for discovering article databases and displaying a menu showing different databases that contain the same article. Publishers seldom provided stable links to articles. Staff had multiple ways to create durable links and add the EZproxy prefix for remote access. A SFX menu of choices was then a user's benefit. When the link to one database was broken, users could fall back on another. However, users simply wanted one click to the full-text document itself. Students expressed a strong preference for direct links in two Distance Education end-of-term surveys in 2006 and 2007. Recently, some publishers or database aggregators (e.g. ProQuest, Ebscohost) provide persistent links to journal articles or downloading mechanism of specific chapters in ebooks (mostly scientific and engineering). This has facilitated Ryerson's return to the direct links method, providing the instant access to full text desired by students

\section{Ares instant statistics look up}

In tune with the new trend of instant access and gratification of demands, instructors are able to check instantly in the Ares system students' usage - how many times a document link was 
opened, at which time of the day and even who these students were, unless the library changes the settings.

\section{Concept Two: One-Stop shopping convenience}

The OCLC 2005 survey of U.S. libraries indicated that $82 \%$ of "information consumers" started their search using a search engine, and only $1 \%$ with library web sites. The number of Google users has surged from 1/3 of all U.S. information searchers in 2005 to 2/3 of users (OCLC, 2010). Users of today are suffering from "information overload". The emergence of federated searches and "discovery" tools such as Summon (Serials Solution) and Ebsco Discovery Service are modeled on the Google-style approach of searching across a unified index of available scholarly publications, combined with local content such as the library catalogue, instead of each database separately. In a survey of 260 academic libraries in North America (Hofmann \& Yang, 2012), the use of a "Discovery" tool has doubled in the last two years, from $16 \%$ to $29 \%$. According to the 2012 report ( ACRL, 2012) on top library trends, “... although campus Information Commons, with cafés and 24/7 access to the facilities and resources, still are popular with students and faculty, convenient access to resources, whether human, print, or electronic is the most critical factor. After all, 'If it is too inconvenient, I'm not going after it'..."

\section{Single sign-on to Blackboard and E-Reserve}

Ryerson's e-reserve service is keeping pace with this "one-stop" concept. It plunged right into delivering e-reserve content through Blackboard, the University's learning portal, rather than staying in the integrated library system. E-Reserve recognized that students wanted a single logon. Having logged into Blackboard, they did not want a separate library password for controlled access off campus. The implementation of the EZproxy server in 2008 for library authentication was a welcome solution.

\section{Merging course readings - print reserves, e-reserves and course packs}

Course readings can be delivered in different formats - print reserves, e-reserves and printed course packs. At Ryerson, the latter is administered by the Campus Bookstore. The rapid copyright changes in Canada contributed to Ryerson's merging of these services into one package, branded as "One-Stop Course Readings". Launched in April this year, the interim goal is to channel all faculty course reading requests, regardless of print or electronic format, to the EReserve library department, for pre-checking of copyright compliance. Time is not ripe yet for a full-fledged digital course pack production. Nonetheless, one silo has been broken down.

\section{Copyright as catalyst to one-stop shopping}

The struggle between colleges and universities in Canada with Access Copyright, the non-profit collective representing publishers, at the expiry of the old "model" licence in 2010, has brought about a new recognition of risks associated with copyright infringement or negligence. Copyright 
officers/coordinators are suddenly in demand, promoting copyright education and implementing policies that protect the institutions from unwittingly breaking the law. Across the border, the lawsuit between Georgia State University and three academic publishers (Oxford, Cambridge and Sage) was a prominent case involving e-reserves. Publishers accused professors and students of copying thousands of documents, thus upsetting the balance between creators and users of works. In Canada, there is increased acceptance of an infrastructure to support copyright control. Universities acquire systems that keep track of transactional licences, document payment and expiry of the content links accordingly. Ares, a system developed by Atlas and distributed by OCLC, is one of such systems, and Ryerson is among the first group of Ares system users in Canada.

Fast on the heels of importing the course pack data into Ares, another initiative was the integration of copyright permissions for digitized audiovisual content in the Library and the requests data from the Distance Education Department on campus. The segregation of the Ares system into compartments, with respective work queues - Library e-reserves, Audiovisual, the Bookstore course pack and Distance Education, is at the experimental stage. Another possible partner is the Institutional Repository (Digital Commons), administered by the Library, for scholarly output in the University. The goal is for the Ares system to become a central copyright repository, with E-Reserve being the custodian of such a convergence.

An article (Williams, 2009) discussing new libraries roles cited two main ones: "as leader in areas such as information literacy, copyright and authors' rights and as provider of extraordinary information experiences - that is, engaging fundamentally in the lives of students, scholars, and citizens to improve individual productivity and the achievement of their goals". Ryerson ereserve experience in the copyright area is fulfilling a part of this new role of libraries.

\section{Concept Three: Customization, personalization and interaction}

Today's user behaviour is characterized by the desire to interact with one another. Social media such as Facebook and Twitter, has become almost a necessity for all walks of life. Blogging is self-expression and personalization. The new generation of users - Millenials or "digital natives" would want such experience to cross over to the study mode. McLoughlin and Lee (2008) cited personalization, participation, and productivity as the three P's of pedagogy. Journal databases have attempted to personalize search results by inviting users to sign into "My Ebscohost", add to folder, and tag or organize found items. Interaction, engagement and "getting in the flow of users" (Williams, 2009) become the new norm of library services.

\section{The RefWorks sharing concept}

Ryerson's e-reserve has gone through stages of customization and personalization. The most restrictive was the library catalogue - searching by instructor name and course code and displaying an alphabetical article title list, with limited bibliographic details. The shift to Blackboard allowed instructors to create sub-folders of readings, sorted by topics or weeks. In 
2007, Ryerson E-Reserve experimented with a citation management software, RefWorks, to encourage interaction between teachers and students. Besides organizing information resources, instructors could set different levels of access to the subject folders they created. By opening up such access, students could ask questions or comment on a particular course reading, and teachers or peers could respond, facilitating an exchange of ideas. Obviously, it could not compete with the "crowd" participation, or "like" or "dislike" mode of the Facebook-style of computing environment but it has added value to the dissemination of information.

\section{The Ares tags, hot lists, email alerts and file exports}

E-Reserve's adoption of Ares in 2011 was another attempt to encourage personalization and customization of content. Faculty can create their own course readings, any time they want, without waiting for library staff assistance. Instructors can "clone" or renew document items used in a previous semester. Instructors can "tag" these materials by weeks, by topics, etc. and sort them by author, journal title, article title, or search by keywords or tags across the courses they teach. The newest Ares release allows instructors to export a list of their course readings to Excel or other external file for local customization. Students can re-tag the assigned readings using their own criteria e.g. exam readings. They can create a "hot list" of readings across courses, consolidating them by a common theme. By subscribing to the "alerts" in Ares, students will get an email notification of new e-reserve items added to their courses.

\section{Concept Four: Integration, collaboration and convergence of services}

The IMS White Paper (McLean \& Lynch, 2004) recommended libraries to focus on serviceoriented architecture, "such as web services, that could involve a series of applications covering the OPAC, e-reserves, portals and document delivery services." The Association of Research Libraries (2009) predicted that in the 2015 technology environment, "Library-centric standards would be taken over by the ability to apply Web-enabled 'external standards': to achieve that blending into a broader information environment that would be user-centric and service oriented."

\section{Integration with Blackboard and responsiveness to technology}

Ryerson's e-reserve experience reflects a general trend towards the CMS, the broader information environment. The Educause Core Data Survey (Hawkins \& Rudy, 2007) showed a 93\% rate of institutions adoption of CMS in the U.S. Lawrence (2006) emphasized that the future of libraries must insert themselves in the CMS to "preserve/reinvent their symbolic place in the institution". A later study (Jeffryes, 2011) confirmed this concept. E-reserve is the first Ryerson library service that successfully integrates with Blackboard, the campus information architecture. E-Reserve staff obtain course builder roles in uploading document links directly into faculty's course shells in Blackboard. With a dummy student account, library staff can assist students by looking up their course content in Blackboard, from the students' perspectives. 
Without this quasi faculty role, other libraries, like the University of Toronto in Canada, have to create a building block to connect course readings to Blackboard.

The Ares system was acquired in 2011 on the understanding that the two systems - Blackboard and Ares would be integrated seamlessly. Both instructors and students continue with single sign-on through Blackboard. A direct "course readings" link is created from the tools menu in Blackboard to Ares so that students can be taken directly into the Ares space. E-reserve staff benefit from working in an integrated system, processing requests, keeping control of copyright, expiring document links automatically based on contract terms, and generating statistics easily. The Ares built-in Z39.50 feature facilitates checking of local holdings while a direct gateway to the CCC (Copyright Clearance Center) in the U.S. speeds up the search for cost information or placing orders directly. In the new Ares release, emails can be sent directly to rights holders and permission documents uploaded to a digital archive. "Addons" e.g. connection with catalogue, Google Scholar or databases, are customized features to expedite processing. One successful example in the U.S. is the University of Chicago's link to their library catalogue. Relevant bibliographic or location data auto-populates the Ares fields, thus saving staff time in manually copying and pasting.

\section{Partnerships on campus}

The Distance Education department has been a major e-reserve user at Ryerson. The latest partnership is the integration of their copyright permissions data into Ares. The campus computing services, the Blackboard administrator, plays a key role in firewall maintenance and pointing the Blackboard building block to the Ares server. Ares will not function in Blackboard if instructors have not created a Blackboard course shell, administered by the Computing department. E-Reserve takes advantage of this close relationship and offers partnership service to the Blackboard walk-in clinics offered throughout the academic year. The latest endeavour to partner with the Bookstore for course pack production extends these collaborations, with the ultimate hope of converging services on campus that share a common purpose and similar clientele.

\section{Other integration tools and co-ordination}

Ryerson's E-Reserve is responding to every change in technology. It makes use of "Search Everything", the Library's Summon tool, to search by article title across the information architecture. E-reserve utilizes the rights usage database created by Scholars Portal (a service of the Ontario Council of University Libraries), checking for rights including links, CMS, course pack, and interlibrary loans of journal titles. The new Copyright Coordinator, hired in November 2011, is closely associated with E-Reserve, though charged with the responsibility of coordinating copyright education, advice on policies and implementation across the university. The Library thus becomes the default leader in the copyright education campaign.

\section{Conclusion}


E-Reserves' importance and influence have often been neglected because of a narrow definition to equate the service to an electronic counterpart of print reserves. In more recent years, libraries and librarians have applied different thinking to this concept, redefining its role in the teaching/learning process. E-Reserves range from "full service", with staff responsible for the whole process, including copyright analysis and payment and uploading links, to the "self service" model, empowering faculty to handle their own course readings and to create persistent links. Faculty are given a choice between the catalogue or the CMS, or both. Institutions can build a link, like Ryerson, between e-reserves and a CMS. Ryerson's Ares/Blackboard e-reserve pilot in 2011 has seen faculty requests skyrocketed, from about 4,000 article links in 2010 to 13,350 in 2011. An even more significant increase is anticipated for the Fall term beginning in September 2012, because of copyright changes and the "One-Stop Course Readings" pilot. Scanned book chapters are forecast to explode in numbers because the new "model" licence signed with Access Copyright, the collective representing publishers, allows "digital" copying to apply the same terms as for paper copies.

E-reserve operations are evolving to become a part of the e-learning environment that combines technology and the new user culture. Ryerson's e-reserve is a good example of the evolution - a part of the e-learning process that redefines the role of academic libraries. The new age of academic libraries will be user-centric, technology driven and collaboration-oriented. Ryerson's e-reserve development mirrors them all.

\section{References}

ACRL Research Planning \& Review Committee (2012). Top ten trends in academic libraries: A Review of the trends and issues affecting academic libraries in higher education. College \& Research Libraries News, 73(6), 311.

The Association of Research Libraries (2009). The Research libraries' role in repository services: Final report of the ARL Digital Repository Issues Task Force. Retrieved from http://www.arl.org/bm doc/repository-services-report.pdf

Carver, D. (2010). Organizational models and roles. Journal of Access Services 7 (2), 72-83.

Cheung, O, Thomas, D. \& Patrick, S. (2010). New approaches to e-reserve: linking, sharing and streaming. Oxford: Chandos Publishing.

Hersey, D.P. (2005). The future of access services: Should there be one? Journal of Access Services, 2(4), 1-6.

Hawkins, B. \& Rudy, J, (2007). Educause Core Data Service fiscal year 2007 summary report, 
33. Retrieved from http://net.educause.edu/ir/library/pdf/PUB8005.pdf

Hofmann, M., \& Yang, S. (2012). "Discovering” what's changed: a revisit of the OPACs of 260 academic libraries. Library Hi Tech, 30 (2), 253-274.

Jeffryes, J., et al. (2011).Integration innovation: Launching the library into a course management system. Journal of Library Innovation, 2(1), 20-34.

Lawrence, D. (2006). Blackboard on a shoestring: Typing courses to sources. Journal of Library Administration, 45 (1/2), 245-265.

McLean, N. \& Lynch,C. (2004). Interoperability between library information services and learning environments - bridging the gaps: A joint white paper on behalf of the IMS Global Learning Consortium and the Coalition for Networked Information. Retrieved from www.cni.org/wp-content/uploads/2004/05/CNIandIMS_2004.pdf

McLoughlin, C \& Lee, M. (2008). The three Ps of pedagogy for the networked society: personalization, participation, and productivity. International Journal of Teaching and Learning in Higher Education, 20(1), 10-27. Retrieved from http://www.isetl.org/ijtlhe/pdf/IJTLHE395.pdf

OCLC Online Computer Library Center, Inc. (2010). Perceptions of libraries, 2010: context and community. Retrieved from http://www.oclc.org/reports/2010perceptions.htm

Poleykett, B., \& Benn, J. (2003). Beyond e-reserve: Implementation of a repository-based reading list management system at the University of Western Australia. Retrieved from http://www.caudit.edu.au/educauseaustralasia07/authors_papers/Poleykett-109\%20FINAL.pdf

Williams, K. (2009). A framework for articulating new library roles. Research Library Issues: A Bimonthly Report from ARL, CNI, and SPARC, no. 265, 3-8. Retrieved from http://www.arl.org/resources/pubs/rli/archive/rli265.shtml. 
